\title{
Beyond the trailing spouse: the commuter partnership as an alternative to family migration
}

\author{
Marjolijn van der Klis · Clara H. Mulder
}

Received: 25 June 2007 / Accepted: 6 November 2007 / Published online: 9 February 2008

(C) The Author(s) 2008

\begin{abstract}
Combining commitments in the domains of work, family, and residence has become a complex puzzle for the contemporary (dual-earner) family, especially when these choices concern family migration. For some families, non-standard alternatives to family migration, such as a commuter partnership in which one partner lives near work part of the time, might provide the best solution in matching both individual and family commitments. Through in-depth interviews with both partners in commuter partnerships, this paper explores the commitments that form the basis underlying the choice for a commuter partnership as an alternative to family migration or not migrating. It further describes how the balance in partners' individual and their common interests, as well as the gender ideologies the couple holds, influence the choice for a commuter partnership. Our findings suggest that the commuter partnership is regarded as a suitable compromise between several commitments not only for partners who are both oriented towards their employment careers, but also for couples who have distinct commitments in their private lives. Partners in egalitarian partnerships were found to view the commuter partnership as a household arrangement that fitted their approach of reinforcing each other's interests and commitments. For couples with non-symmetrical gender beliefs we found that in order for one (usually male) partner to pursue a choice biography through the commuter partnership, substantial sacrifices were demanded from the (usually female) spouse.
\end{abstract}

Keywords Choice biography - Commuter partnership · Family migration · Gender · Life course · Trailing spouse

\section{Introduction}

In recent years, the relationship in post-industrial countries between work, family, and residence has become complex owing to regional differences in housing and labour

M. van der Klis $(\bowtie) \cdot$ C. H. Mulder

Amsterdam Institute for Metropolitan and International Development Studies, University of Amsterdam, Nieuwe Prinsengracht 130, 1018 VZ Amsterdam, The Netherlands

e-mail: m.vanderklis@uva.nl 
markets and the growth of dual-income families. A range of geographical research has shown that, in order to run a household effectively, spouses have to make compromises between individual and common careers. In choosing a residential location, they negotiate about the distances to their jobs, the divisions in household responsibilities, and the type of setting in which they prefer to live (for example: Bailey et al. 2004; Droogleever Fortuijn 1993; Fagnani 1993; Green 1995; Hardill et al. 1997; Karsten 2003; Hochschild 1997).

Family migration decisions are especially difficult because of the simultaneous impact in residential, work, and family domains for all the family members (Clark and Davies Withers 2002). Both individual preferences of partners and their common interests influence the decision whether or not a family migrates; as do external circumstances (Bailey et al. 2004; Mulder and Hooimeijer 1999). Furthermore, there is a major influence of gender dispositions on priorities and concessions made by individual partners (Beck and Beck-Gernsheim 1995; Hardill 2002). Gender roles play an important part in whether or not couples migrate (Cooke 2003; Halfacree 1995; Jürges 2006). If couples do migrate, one of both partners likely follows the other as a trailing spouse (also called tied mover); if they do not, the other partner may become a tied stayer (Cooke 2003; Mincer 1978).

Probably because of the growing complexity of migration decisions, there is a growing variety in the geographical organization of contemporary households, including nonstandard arrangements such as recurrent mobility between two residences (Haskey 2005; McHugh et al. 1995). One specific non-standard living arrangement is the commuter partnership (adapted from 'commuter marriage', the term used by Gerstel and Gross (1982, 1984), to include couples living together unmarried). Here, one partner lives near his or her work for part of the time and away from the communal family home, because the commuting distance is too great to travel on a daily basis. Commuter partnerships, which are expected to grow in number, can be understood as an alternative geographical arrangement to either family migration or not migrating. The choice for two residential locations is most likely a compromise between commitments made in the life domains of work, residence, and family. Understanding this choice would be helpful not only in explaining how this specific living arrangement comes into existence, but also in developing a more nuanced view of family migration decisions: apparently, some couples do not just decide for or against family migration, but choose a third option.

The limited number of previous studies into commuter partnerships show that occupational reasons always form a major part of the rationale to opt for this geographical organization of the household (Anderson and Spruill 1993; Gerstel and Gross 1982, 1984; Green et al. 1999a, b; Gross 1980). Family and residential circumstances sometimes also play an important part in starting a commuter partnership (Green et al. 1999a, b). These studies further indicate that the benefits and concessions related to the commuter partnership are for many couples not shared evenly between partners, which frequently relates to gendered differences. These studies thus provide useful insight into the choice for a commuter partnership. However, more research is necessary to improve this insight and to connect it with research into intra-household decision making about family migration.

The aim of this paper, therefore, is to gain a better understanding of the choice for a commuter partnership as an alternative to either family migration or not migrating. The research questions addressed are: To what extent do couples consider the alternatives of migrating or not migrating as a couple before opting for a commuter partnership? How are the commitments leading to a commuter partnership related to the life domains of work, family and residence? How can the choice for a commuter partnership be explained in terms of individual and common interests and gender dispositions within the partnership? 
After further elaborating on the scholarly concepts to be applied here and clarifying the context and methods, we look into the experiences of commuter partners using evidence from sixty in-depth interviews with both partners in thirty commuter partnerships. At least one partner in every couple lives in the Netherlands permanently. Before arriving at our conclusions, a typology is presented to give insight into most of the diversity in intrahousehold considerations and the choices that have led to the commuter partnership.

\section{Previous research and theory}

To create insight into the choices of individuals in different life domains over the life course, the life course approach is useful for our analysis (Elder et al. 2003). A range of life domains or careers can be distinguished, such as the occupational, educational, residential, family, and partner careers (Willekens 1991). In each of the life domains, individuals can set priorities that can develop into commitments. Commitment can be defined as a life choice that has long-term consequences that cannot be changed at all, or only at a high cost. A crucial characteristic is that a commitment in one domain can have consequences for other domains that are not necessarily related to the commitment made (Becker 1960; Feijten et al. 2003; Mulder 2002). Over the life course, coordination between the choices made within the different domains is needed because of potential conflicts between different commitments (Willekens 1991). When priorities have to be set, a specific career orientation might be decisive. If an individual holds a dominant orientation towards a career, for instance an occupational career or a residential career, the commitments made in this domain will outweigh other commitments. A dominant orientation might originate in a certain phase of one's life, in which case the dominance might shift towards another domain later in the life course (Bell 1968). Career dominance can also be related to an individual's lifestyle, which is usually of a more durable nature. Lifestyle can be defined as the long-term orientation towards the importance of different life domains (Bootsma 1998).

The findings from several previous studies on commuter partnerships seem to suggest that these partnerships are characterized by a career dominance of labour-market careers for both the male and the female partner in the couple (Anderson and Spruill 1993; Bunker et al. 1992; Gerstel and Gross 1982, 1984; Gross 1980). However, these studies all focused specifically on dual-career commuter partnerships. Their findings thus most likely partly reflect the study design. From the scarce research on commuter partnerships that does not focus exclusively on dual-career couples, it became clear that work was indeed a key factor in deciding to start a commuter partnership, but that for part of the couples the residential career was also an important factor in retaining the original residential location besides the new location (Green 1997; Green et al. 1999a, b).

Social scientists have pointed out that, through the individualization of late modern societies, the life course has become contingent and de-standardized; individuals can make their own life-course choices. As a result, many individuals constantly work on a project of the self in order to make the best possible life plans (Beck 1992; Giddens 1991; Sennett 1998). The trend towards de-standardization puts more emphasis on individual resourcefulness and responsibility in shaping one's life course (Heinz and Krüger 2001). The question that rises, is to what extent choices made within the life course can be regarded as conscious strategies (Kuijsten 1999). The routine actions of an individual or household and the unintended consequences of these actions are often as significant as rationallygrounded, goal-oriented strategies (Giddens 1991; Jarvis 1999). Some point out that, in this 
day and age, the notion of individual choice, articulated in the choice biography, might have become too dominant within social-scientific research. The true scope of freedom of individual choice has been shown to have distinct structural limitations (Brannen and Nilsen 2005; Favell et al. 2006). Furthermore, the individual responsibility for the life course also entails substantial risks of failure (Beck 1992; Giddens 1991).

Over the years, numerous studies that looked into choices made by couples and families have shown the importance of a gendered approach (Beck and Beck-Gernsheim 1995; Cooke 2003; Fagnani 1993; Komter 1985). Hardill (2002) points out that individual competitiveness and demands for (spatial) mobility are common in many heterosexual relationships. Common interests may lead one or both partners to expect or feel obligated to give a lower priority to their individual career interests in order to invest in the 'collective project called family' (Beck and Beck-Gernsheim 1995; Giddens 1991; Hardill 2002). In general, women experience less continuity in the life domain of work because of their responsibility for dependent lives (Heinz and Krüger 2001).

Choices within the household are often influenced by family ideology. Through its anchoring in everyday thinking and routine action, ideology can have a strong influence on the strategies within the household (Jarvis 1999; Komter 1985). Alternative ideas about family arrangements are found to influence the choices made within the household (Fagnani 1993; Karsten 2003). The degree of symmetry between partners at the onset of a partnership is found to be a strong indicator of future arrangements between partners (Droogleever Fortuijn 1993). In Gross's (1980) study of commuter partnerships, most couples were found to have a history of shared domestic division of labour.

Within the life-course approach, the individual agent has traditionally been the basic reference. However, as the above-mentioned studies have shown, within families and households, individuals' lives are interdependent (Elder et al. 2003). This means that a decision made by one family member may have unwanted or unintended consequences for other members (Hagestad 1981; Heinz and Krüger 2001). Households can therefore be conceptualized as networks of linked lives (Bailey et al. 2004).

Since Mincer (1978) started the discussion on the different positions of men and women in family migration decisions, an extensive literature has developed on this topic (see Cooke 2003, for an overview). Migration decisions originate most often in the domains of work and education (Mulder 1993). If a job opportunity outside the daily activity space and beyond a reasonable travel time for daily commuting is accepted, migration is usually the only option for the household (Van Ham 2002). Interestingly, migration takes place much more frequently for the benefit of men's careers than for women's. Women are less likely than men to migrate for their own careers, and more likely to be a trailing spouse (or tied mover) who migrates with her partner in favour of his career (Bielby and Bielby 1992; Bonney and Love 1991; Cooke 2003; Markham and Pleck 1986; Mincer 1978). These differences between men and women have decreased over time, but, as Smits et al. (2003) have shown for the Netherlands, they have by no means disappeared. The differences are particularly great for traditional couples, but much less so for egalitarian couples (Jürges 2006). Furthermore, women tend to have lower incomes and a smaller probability of being in (suitable) employment after family migration (Bielby and Bielby 1992; Boyle et al. 2001; Clark and Huang 2006; Cooke and Bailey 1996; Cooke 2003; Jacobsen and Levin 1997; Shihadeh 1991; Smits 1999; Van Ommeren 2000).

Much of the research on family migration has been devoted to testing hypotheses derived from two competing theories of family migration: the human-capital theory and the gender-role theory (Cooke 2003). According to human-capital theory, couples aim to maximize their joint utility or income. They will migrate if they expect this joint utility to 
be increased by moving, even if one of the partners would not benefit individually. Because women generally have lower earnings and a lower earning potential than their husbands, couples are more likely to migrate for the husband's career than for the wife's. According to gender-role theory, migration decisions are subject to the gender-role ideology within the household (Bielby and Bielby 1992). The husband tends to dominate the migration decision even if it is not economically rational for him to do so, and even in situations where the wife has a higher income or higher earning potential. Various studies have therefore concluded that human-capital theory is not sufficient in explaining family migration decisions and that gender dispositions are crucial for the outcome of the decision (Bielby and Bielby 1992; Cooke 2003; Halfacree 1995).

One would expect gender dispositions also to play an important part if the outcome of the migration decision is a commuter partnership. Research by Gross (1980) for the United States indeed suggested that both the male and female partners living in such an arrangement were specifically likely to attach a great importance to the wife's career. It should be borne in mind, however, that Gross's research was restricted to dual-career couples, so the design of her study prevented her from observing male-breadwinner couples.

\section{Commuter partnerships in the Netherlands}

In order to have a good understanding of the choices made by commuter couples, it is important to keep in mind the particular context in which these couples operate. All the couples we interviewed have a residence in the Netherlands. The Netherlands' political economy can be characterized as a form of state capitalism (Albert 1993). Although in recent years there has been a growing orientation toward a neo-liberal model in the Netherlands, the welfare state and protection of the livelihoods of individuals is still strong in comparison with the Anglo-American political economies.

Nowadays, the Netherlands is one of the European countries with the highest participation of women on the labour market, but with the majority of women working part-time (SCP and CBS 2006). Among dual-income households, the most common strategy involves one (usually male) breadwinner and a (usually female) partner in part-time employment. Issues surrounding the sharing of income, household, and family responsibilities within the household are subject to a nation-wide debate.

Within the Netherlands, the largest concentration of employment opportunities is found in the Randstad region, where Amsterdam, Rotterdam, and The Hague are the largest cities. The housing market in this region is highly pressured; prices are high and the available space per property is relatively small compared with other parts of the country. For affordable housing or rural residential styles, households may feel forced to look for property outside the Randstad region. Combining affordable housing with suitable employment may lead to opting for a commuter partnership (for similar findings in the UK see: Green et al. 1999a, b).

The large service sector that characterizes the national economy of the Netherlands has a strong international orientation; this has been strengthened by international treaties such as the European Schengen Treaty. This leads both to the attraction and the sending out of highly-skilled expatriate workers. The growing number of individuals working outside the Netherlands as expatriates, the growth in dual-income households, and the difficulties for the partners of expatriate workers to find suitable employment in the host country have probably led to a growing number of commuter partnerships with one partner working 
abroad, while the other stays in the Netherlands. The conditions for an increase in international commuter partnerships in the Netherlands are further induced by the international hub position of Schiphol International Airport, located near Amsterdam, with a large number of low-budget airlines and global destinations to facilitate flying as a regular means of weekly commuting.

It is very difficult to estimate the number of commuter partnerships in the Netherlands. No official figures are available. The only sample survey allowing for an estimation is the Netherlands Kinship Panel Study (NKPS; Dykstra et al. 2005). ${ }^{1}$ From these data it can be estimated that, of the couples with and without children in the Netherlands around 2003, less than one percent lived in a commuter partnership. Whether this number is actually growing is unknown.

\section{Commuter couples studied}

The evidence presented here is of a qualitative and explorative nature. Because of the absence of databases from which commuter couples could be selected, we searched for respondents through networking, advertising, approaching companies, and the snowball method. We used purposive sampling (also known as theoretical sampling) for the selection of respondents (Glaser and Strauss 1967; Mason 1996). Sixty in-depth interviews with both partners of 30 commuter couples were carried out. A set of criteria was determined for the selection of the couples; whether a couple would fit within the framework of the research project was established by a short questionnaire. The main criteria were that at least one of the two residences should be located in the Netherlands and the couples should spend at least three nights a week in the two separate residences (compare Anderson and Spruill 1993); the travel time between both locations should be well above a commuting tolerance for daily commuting; it had to be clear that couples had the basic intention to live in one shared home (in contrast with Living-Apart-Together couples, who prefer separate residences in any event). Furthermore, some differentiation in household characteristics was taken into account in the selection of respondents (see Table 1 for an overview of respondent characteristics). Couples for whom the time spent away from the communal residence was inherent in the type of profession, and in whose situation it is practically impossible for partner and children to come along, such as oil-rig workers, truck drivers, travelling sales representatives, and navy employees, were excluded from the study.

The partners were interviewed separately to enable each respondent to reflect on the choices that led to a commuter partnership from an individual point of view (Valentine 1999). The interviews were conducted using a topic list. Apart from bringing up the topics, the interviewer steered the respondents as little as possible, and allowed the respondents ample time for telling their stories in the way they liked. The narratives of respondents, in which they reflected on their experiences, were complemented with biographical information about the work, residence, and family careers obtained from an additional short structured questionnaire.

Most respondents were highly educated and employed in specialized professional or managerial positions. Half the couples commuted between two locations within the Netherlands; the rest had one residence in the Netherlands and another residence abroad

\footnotetext{
1 The Netherlands Kinship Panel Study is funded by grant 480-10-009 from the Major Investments Fund NWO, and by the Netherlands Interdisciplinary Demographic Institute (NIDI), Utrecht University, the University of Amsterdam and Tilburg University.
} 
Table 1 Characteristics of commuter partnerships in this study (total of 30 couples)

\begin{tabular}{|c|c|c|}
\hline Characteristic & Category & Number of couples \\
\hline \multirow[t]{4}{*}{ Age categories of partners } & Under 30 years & 3 \\
\hline & $30-40$ & 5 \\
\hline & $40-55$ & 17 \\
\hline & $55+$ & 5 \\
\hline \multirow[t]{2}{*}{ Commuting partner } & Male & 21 \\
\hline & Female & 9 \\
\hline \multirow[t]{2}{*}{ Dependent children in family } & Yes & 15 \\
\hline & No & 15 \\
\hline \multirow[t]{2}{*}{ Parent with whom children live $(n=15)$} & Mother & 12 \\
\hline & Father & 3 \\
\hline \multirow[t]{2}{*}{ Countries of residence } & The Netherlands (both residences) & 15 \\
\hline & The Netherlands and another country & 15 \\
\hline \multirow[t]{5}{*}{ Occupation* } & Research/education & 17 \\
\hline & Politics/government/not-for-profit & 17 \\
\hline & Commercial/business & 19 \\
\hline & Self-employed/independent practitioner & 3 \\
\hline & Stay-at-home parent & 4 \\
\hline \multirow{4}{*}{$\begin{array}{l}\text { Contracted work hours per week } \\
\text { of commuting partner }\end{array}$} & $<12$ & 0 \\
\hline & $12-28$ & 0 \\
\hline & $29-36$ & 6 \\
\hline & $36+($ full time $)$ & 24 \\
\hline \multirow{4}{*}{$\begin{array}{l}\text { Contracted work hours per week of partner } \\
\text { at communal residence }\end{array}$} & $<12$ & 3 \\
\hline & $12-28$ & 8 \\
\hline & $29-36$ & 5 \\
\hline & $36+($ full time $)$ & 14 \\
\hline
\end{tabular}

* Counted for the individual respondents

(mainly in countries surrounding the Netherlands, such as the United Kingdom, Belgium, Germany, but also in Switzerland). In one case one residence was located in a nonEuropean country (Bolivia). Apart from this one case, those commuting internationally had travel times that did not differ much from those commuting within the Netherlands and their flight schedules allowed similar weekly commuting patterns. Fifteen couples had dependent children. In each case, the children were living permanently in one communal residence with either the mother or the father, while the other parent commuted to a location near the workplace.

In the analysis of the interview material, the focus was on the narratives of respondents regarding their choice for the commuter partnership. After exploring respondents' considerations for not choosing either family migration or rejecting job opportunities beyond a daily commute, the life domains of work, residence, and family were the guidelines for analysis. Subsequently, the balance in individual and common interests and their gender dispositions were of key importance in the examination of respondents' stories. Finally, a typology was developed inductively. The aim of the typology is to give insight into the diversity of considerations that can lead to opting for a commuter partnership. 
It should be stressed that part of our findings may be related to our study design: because of the sampling method, we probably have disproportionately selected couples in certain occupations or with a higher level of education. Compared with several previous studies into commuter partnerships, however, our sample is less selective: unlike Anderson and Spruill (1993), Bunker et al. (1992), Gerstel and Gross (1982, 1984), and Gross (1980), we did not restrict our sample to dual-career couples.

\section{Findings}

\subsection{Considering family migration}

The commuter partnership can be regarded as an alternative to either family migration or the entire family not migrating (by the rejection of all job opportunities at a distance beyond a reasonable daily commute from the family residence). The first question raised was: To what extent do couples consider the alternatives of migrating or not migrating as a couple before opting for a commuter partnership? Interestingly, commuter couples themselves regularly feel that they do not really have a choice. In their experience, there was no realistic alternative solution at the time they made the decision to start the commuter partnership: "At that moment it seemed the most logical option". 2

Another general finding is that the stories of the two partners in a couple about the considerations leading to a commuter partnership are nearly always very similar, despite the fact that they were interviewed separately. This is also true of their descriptions of the role of the various life domains in their partnerships and of individual and common interests. In the remainder of the paper, therefore, we often refer to couples' rather than to individuals' considerations and experiences.

Some couples give thoughtful consideration to their personal preferences and the available options and discuss them carefully. They try to prevent a dual residence situation by searching for jobs within commuting distance from their family residence, but come to the conclusion that no suitable employment is available. Others think about migrating to the new job location, but decline that option because they consider the residential environment to be unsuitable or too disrupting for their family, especially if family migration would entail international migration.

Some couples deliberate extensively on the possibility of a commuter partnership before applying for a job at a greater distance from their residence. However, when a concrete job offer does come up, these couples usually have to decide what to do at once (within 1 or 2 days), which leaves some overwhelmed when they grasp the impact of the consequences of a commuter partnership.

Many couples, however, never consider the alternatives to a commuter partnership seriously. Some expect the commuter partnership to be of a temporary nature and are of the opinion that moving the family for short-term reasons is not worth the trouble. In the case of dual-career couples, the partners often conclude that finding two jobs in one region is more or less impossible and therefore decide that searching for them is a waste of time and energy. While some couples were not happy about their choice, most regarded it as a positive or at least neutral solution to their migration dilemma.

\footnotetext{
2 To protect the privacy of the respondents in this study, the interviews were made anonymous. Quotations are used to illustrate remarks that were characteristic of narratives of various respondents on the same topic.
} 
In conclusion, for many of these couples the choice for a commuter partnership is not necessarily the outcome of a conscious mobility strategy, but rather the product of a bundle of interrelated decisions about their personal commitments and the available options.

\subsection{Commitments in the life domains}

The choice for a commuter partnership is strongly determined by the life domains of work, family, social networks, leisure activities, and residence in which commitments are made. In the narratives of various commuter couples, the distinctions between several of the life domains are not very sharp. These respondents regard the domains of residence, family, social networks, and leisure activities as part of one accumulative domain of the private life, which is distinguished from the work life. For analytical purposes, we distinguish between commitments in the work, residential, and family domains, following the most common division of domains found in the life-course literature (Elder et al. 2003; Willekens 1991). The second question we explored was: How are the commitments leading to a commuter partnership related to the life domains of work, family, and residence?

Work domain. Because of our selection of respondents, the commitments that initiate a commuter partnership always include the work domain. The job of at least one partner is a crucial factor for all commuter couples. In many cases, both spouses' jobs are considered key in their choice for a dual-residence situation. The high levels of professional specialization and education of most of these couples leads to partners having only small pools of job opportunities that fit their educational profiles and personal occupational demands. This scarcity raises difficulties in finding one, let alone two suitable jobs within the daily activity space of the family residence. The considerations of couples are sometimes related to societal factors such as the employment structure in the region where the couple lives. Following reorganizations set up by the employer, a few respondents feel they have to accept an offer at another location of the company, because they see no way of finding another suitable job in their communal residential area.

In dual-career commuter families, both partners value their working careers as a major part of their personal lives, and often also of their spouse's life. Amongst these respondents an attitude that might be called an ideology of professionalism is abundant. Here, a strong commitment to a profession, often amounting to a high rate of professional specialization, is characteristic. The personal identity is strongly shaped by one's profession and attitude towards work.

For some, career phase is a factor that adds to a strong work commitment. Realizing that one is in the middle of a crucial period for giving direction to a professional career is sometimes a central part of prioritizing the work domain. This view can be related to the start, the establishment, or the final career phase.

Risk assessment in the work domain also plays a part in the choice for a commuter partnership. Some commuters do not want to risk letting good employment opportunities outside the daily activity space pass by in order to stay put with their partner at the family residence. Similarly, others regard quitting a high-quality job in order to follow a spouse in family migration as too great a risk for their occupational careers. Interestingly, this risk is felt in all age groups and career phases. Those who are at the onset of their careers believe it is too risky for their upward mobility on the career ladder. They sometimes mention that, had they been more established in their career, they might have taken a chance at being a trailing spouse. Older people (predominantly women), however, want to avoid the age risk of unemployment that might result from following their spouse. 
A fifty-seven year old woman who works as the assistant to a board of directors and whose husband was offered a job opportunity abroad remarks: "I felt very strongly, I don't believe that I will give up my job. I did begin as a secretary once, and so I thought I could be a secretary again over there. But that would be stupid; I now have a super job, so I'm not going to do that. (...) If I had been younger I might well have taken the risk, and thought when you come back then I'll take it up again, but now I don't think that would be a good idea." (Mary)

A number of people (mainly men) opt for a second residence near the workplace, because they are constrained in their journey to work by the growing problem of traffic jams that is manifest in the Randstad area of the Netherlands. This congestion pushes their commute over a maximum time for a daily commuting tolerance. Others make use of the contemporary travel opportunities provided by the growth in air travel, which has led to an expansion of opportunities for working abroad. Even if the employer does not pay for travel expenses, there is ample opportunity for cheap travel through low-budget airlines.

“... I enjoy living abroad. And in my job, I have become quite a specialist since I began work. So in the Netherlands there are perhaps only three other people with the same job among our competitors. So you soon find yourself having to go abroad, and I wanted to go abroad. At one time it came up that I would go to Brussels, but it ended up to be London." (Dan)

Residential domain. There are couples for whom the family residence and the residential environment are of such significance, they opt for a commuter partnership in preference to leaving through family migration. Some couples, for instance, opt for a rural setting, attaching great value to the combination of rural qualities for the relatively low cost of living away from the Randstad region of the Netherlands, where most employment opportunities are concentrated (for similar findings in the UK see: Green et al. 1999a, b).

Some commuting partners point out that the commuter location (the residence near the workplace) also has location qualities to which they attach value. London, for instance, was attractive to some respondents for its metropolitan atmosphere and Switzerland was appreciated for the outdoor opportunities the Alps provide. However, generally no priorities other than the job opportunity motivated the choice for the commuter location, so that the specific commuter location was selected primarily because of the employment opportunity provided in that place.

National rules and regulations in the residential domain sometimes put constraints on commuter couples. In the Netherlands, it was not until the late 1990s that the law allowed married spouses to be registered in two separate residences, creating administrative difficulties for commuter couples. They were obliged to search for illegal residential solutions or were dependent on the understanding and cooperation of local officials.

“... I couldn't get a residence permit just like that. I was informed by the local authority that according to the law I should be living with my husband. I was absolutely furious, and I thought, we'll see about that. (...) And they actually had to cook up an arrangement, because there was a legal precedent ruling of a woman who could not get a residence permit because she was obligated to live with her husband." (Flora)

Although the obligation to live in one residence has recently been lifted, other inequalities in the residential domain remain. Mortgage tax deductibility in the Netherlands applies to 
primary residences only, so that commuter couples are forced to apply for special approval from the Treasury to make use of this tax deductibility in a dual-residence situation. Also, for some couples the transfer taxes for homeowners (about ten percent of the selling price) lead to the choice for commuter partnership instead of family migration in order to avoid financial loss on the selling and buying of a home. Furthermore, a risk that not everyone is willing to take is to sell a residence in a region of a lower price range and acquire a home in a more expensive part of the country.

Family domain. In the family domain, two sorts of commitments are found: on the one hand those to dependent children and on the other hand the commitments of partners to each other.

All commuter families (commuter couples with dependent children) are committed to the stability of their children. That the children need to live in one stable location and are not to be moved around on a regular basis is invariably beyond dispute. Respondents point out that they do not want to disrupt the adolescent years of their teenage children by family migration and believe that it is less disrupting for one parent not to be around for several days a week. The adolescent children are sometimes consulted by their parents before they embark on a commuter partnership.

In different life phases, couples might regard a commuter partnership as a suitable solution for combining each other's individual preferences without forcing one or the other to let opportunities pass by in order to live in one shared location. This feeling applies particularly to couples who do not have dependent children living with them: couples in their twenties or early thirties at the onset of their family career, those who are voluntarily childless, or empty nesters who have left the period of daily care for their offspring behind. Some couples with dependent children are found to apply the same style of reasoning.

Couples who were at least in their thirties when they formed their union often regard the commuter partnership as a good compromise for combining their partnership with individual commitments. Both partners in these couples developed strong individual commitments when they were single, which have to fit within their partnership. This type of consideration can be expected to become more common in the demographic context of a rising age of partnership formation in post-industrial societies.

Monique and John met when they were in their thirties. At first Monique moved to the Randstad to live with John and found a new job over there. However, when they prepared to have children they decided to create a family home in a rural area near Monique's place of birth. Monique doesn't have any problem with her husband being away for four days a week and expects this situation to be of a permanent nature: “... I think that John will still be working there when he is 65 , that's what I think." About her own situation she remarks: "now... I've lived alone for a long time, and John has also lived on his own for a long time. So I don't find it a problem to be alone in the evening, because then I can do whatever I please. (...) I don't find it unpleasant, I enjoy it."

In conclusion, this part of the analysis has shown that in the work domain professional growth is vital, but so are the limited job opportunities. In the residential domain, lifestyle preferences are important, but so are the constraints caused by regulations and housing markets. In the family domain the wellbeing of the children and of both individual partners are weighed up and balanced with the common interests. The fact that some of the people interviewed did not distinguish between the residential and family domains, but thought rather in terms of one private life domain, shows how bundles of considerations throughout all spheres of their lives are at stake for commuter couples. 


\subsection{Priorities within the partnership}

The decision to opt for a commuter partnership is determined not only by the life domains in which priorities are set, but also by whose commitments are prioritized: his or her individual preferences or their common interests. The considerations that underlie the choice for a commuter partnership can be viewed as an expression of the degree of symmetry between partners. This is strongly influenced by gender dispositions toward professional and household responsibilities and ideologies regarding individuality within the framework of the family. In this part of the analysis we explore the question: How can the choice for a commuter partnership be explained in terms of individual and common interests and gender dispositions within the partnership?

We found that the commuter partnership is sometimes the expression of an egalitarian partnership, in which partners' rights and responsibilities are evenly shared. Both partners have strong commitments of an individual nature. Both also value each other's individual commitments as an important foundation of their partnership. Both consent to a commuter partnership, because neither wants to force the other to be fitted into his or her individual life project; they do not want their partner to be a trailing spouse with the risks this might entail for this partner's occupational career. They live by what Gerstel and Gross (1984) named an ideology of independence. For some couples, the perception of independence and individuality is so fundamental to their partnership that they stimulate each other intentionally and mutually to stand by their individual life plans. These couples are examples of putting into practice Giddens' (1991) concept of the pure relationship, in which the partnership is valued especially on account of the inspiration that is brought into the relationship from the individual life experiences of both partners. This is a partnership characteristic that according to Giddens is symptomatic for late modern societies.

Jenny is a thirty-four-year-old politician, whose partner is also in politics. They have a three-year-old child. Jenny generally spends four days a week at her work location. She remarks: "It is certainly convenient to have a partner who understands why you sometimes agonize over something for a whole weekend and who doesn't just think that you have an anxious personality, but realizes that you are really involved in something that matters to you. (...) We clearly have something in common, our motivation and drive, apart from the fact that the two of us really enjoy being together. But that you can put those things together."

For other couples, the commuter partnership is a solution at the couple level for combining the preference of one partner to develop in an individual career with the other's priority for the common commitments of the household. In general, these couples share a traditional gender ideology, with the male spouse pursuing an individual career, usually a work career, while the female spouse lets the communal interests of the family prevail. The balance in power of decision and control within these partnerships is of an asymmetrical nature and can be described as the power of custom and practice (Komter 1985).

Margaret's husband works at the international headquarters of a company that is located in a large European city. Margaret stayed put in the Netherlands with their three young children. Int: "and how did you come to that decision?" Resp: "we talked about it for a long time, I found it very difficult. I did say: 'that wasn't what I got married for, not to see my husband through the whole week'. And yes, I had a difficult time agreeing with it, but finally as he was so interested in that job we decided that we really had to do it." Int: "And did you have the feeling that you took 
the decision together?" Resp: "yes of course, yes, we decided on it together. It didn't just come from one side. I wouldn't do that either [laughter]."

For yet other couples the commuter partnership can be regarded as a form of postponing the long-term commitment to each other and the relationship, which will ultimately require one or both partners making sacrifices in order to live in one residence. In these couples, who are usually in the life-course phase prior to having children, the individual preferences are put before the common interests. The stories of these couples indicate that they do not expect this gender symmetry in how they prioritize to continue in the long run. These couples indicate that eventually they will commit to living together full time. Their family ideology does not allow for a commuter partnership when they have children. However, the sacrifices it might entail for one or both partners to realize this commitment to their relationship are usually denied in the interviews or kept vague.

Caroline and her partner Dan are in their late twenties. Both partners specifically chose to pursue a working career and not to have children. They see their commuter partnership as a temporary solution within their employment and family careers. Caroline remarks: "Yes, I also think that once you choose to have children, then you have to share that responsibility. And not that you then go and stay in another country or wherever for five days at a time. And then become just a weekend mum or dad. I don't think that is how it should be... Yes, it's possible, but...yes then perhaps if you both want to keep the situation as it is, that would also be a possibility, but then I don't know whether the decision would ever be taken to have children. I mean if you want children and are able have them then you've got to be there for them. That is what I believe."

There are couples who started commuting after becoming empty nesters. For these couples the commuter partnership is related to a move towards more individuality and symmetry within the partnership after the childrearing life phase has been concluded. These couples raised their children in one shared residential location, usually within a framework of traditional gender roles with the female spouse combining work and family responsibilities and the male partner primarily focusing on his employment career. After becoming empty nesters, the women in particular grasp the opportunity finally to put themselves first, an attitude which their husbands usually support.

Flora and Theo started a commuter partnership shortly after their youngest child had gone to college. For Flora, the choice for two residences is strongly related to the opportunity for individualizing she saw after becoming an empty nester. Resp: “Oh, what I've got to tell you here! At the time when I came here to live, I did many other things. We had been married for twenty-five years, the children had left home, I went back to using my own name. That I had never previously wanted to do, because I wanted to belong to the children. (...) And of course everyone has that feeling, when the children have left home than you think now OK, now I've got the space to follow my own path. And that then was the way that it went for me." (...) Int: "If the children had still been at home, would you in that case have chosen for two separate residential locations?" Resp: "No, certainly not, absolutely not. I am quite sure about that."

The choice for a commuter partnership is sometimes strengthened by the couple's past experiences with non-standard solutions, such as one or both partners travelling extra long daily commutes or partners periodically alternating their roles of primary financial provider and primary homemaker. For these couples the matching of the preferences of each 
individual partner is always open to alternative solutions and not subject to predisposed gender dispositions. They have incorporated non-standard household solutions in their lifestyle.

Rick, a father of two teenage children remarks: "When the children were small, Paula worked full time and I looked after them. (...) Later, I took a part-time job. At that time I worked in [town 2.5 hours journey away] and travelled back and forth on two days a week." After that period, the family spent several years abroad for Rick's job. The family returned when the oldest child was going to secondary school. From that moment, the couple has had a commuter partnership within the Netherlands. Both partners indicate that as soon as their youngest child goes to college in a couple of years time, they will reconsider their residential and employment commitments.

In conclusion, this part of the analysis shows that couples who opt for commuter partnerships are found both among couples with egalitarian gender dispositions and among those with a traditional family ideology. Whereas some couples regard commuter partnership as an exception to the nuclear family life style, and feel a commuter partnership only fits certain phases in the life course, others have incorporated their choice for a commuter partnership into a lifestyle of non-standard household solutions.

\subsection{A typology of commuter partnerships}

When the analyses based on the three research questions are combined, a typology of commuter partnerships can be formulated in terms of the grounds on which couples opt for such a partnership. A main finding from our exploration that is reflected in the typology is that these grounds show a stronger differentiation in the combinations of the life domains and the balance between individual preferences and common interests than might be expected. Three main types are distinguished.

First, there is the dual-career commuter partnership; seventeen couples (out of a total of 30 couples) can be so classified. In this type, the choice for the commuter partnership is grounded in the commitments of both partners to their occupational careers. These couples are the classic dual-career commuter partnerships that were studied in much of the previous research on commuter partnerships (Anderson and Spruill 1993; Bunker et al. 1992; Gerstel and Gross 1982, 1984; Gross 1980). They are not just dual earners; both partners attach great importance to their occupational careers.

Within this type, a distinction can be drawn between choices that are grounded in life styles and in life phases. First, there are couples for whom the prioritizing of both partners' individual employment careers is part of a life style of individualism and symmetrical gender roles in their partnership. For these couples the commuter partnership itself can even represent a significant symbol of their egalitarian life style. Second, for other couples, the choice for a dual career commuter partnership is grounded in a certain phase in the couples' life course. The commuter partnership is not part of these couples' long-term life style; it is a practical solution at times when the common interests, especially family commitments, do not suffer. This is especially the case when the couple does not have dependent children.

Second, a private life priority commuter partnership can be distinguished (11 couples). These couples apply the traditional gender roles of the male provider and the female homemaker, even though almost all of them are dual-earner couples with the female partner juggling home and work. They name and interpret their dual residence situation 
themselves usually as a weekend marriage. But whereas the gender role divisions of these couples are usually more traditional than for the dual-career commuters, these couples do not live by an ideology of a classic nuclear family. For some couples, prioritizing the private sphere in and around the communal residence expresses that not only the work domain, but-just as importantly-the private domains of family, residence, and social networks provide valid grounds for the female partner not to become a trailing spouse who would follow her husband in family migration.

Third, the economic necessity commuter partnership is distinguished (two couples). The importance of distinguishing this type of commuter couple is found in the impact of societal factors on individual agency. For these couples, the alternative option of the entire family staying put as to avoid a commuter partnership implies unemployment or a degree of underemployment that would lead to a substantial drop in income, and the option of family migration is regarded too full of risks, financially and sometimes also emotionally. In contrast with the other two types of commuter partnerships where the priorities are about self-fulfilment, these couples' grounds are rather about basic needs. The societal context of the Netherlands, where regional economic differences influencing family income and risks of unemployment are relatively small due to national welfare policies providing safety nets of social benefits, suggest that this type of commuter couples will be relatively small. However, in countries with stronger liberal market economies such as the UK or the USA, the grounds of couples to opt for a commuter partnership might be found in economic necessity more often.

\section{Conclusions}

In this paper we raised three questions: To what extent do couples consider the alternatives of migrating or not migrating as a couple before opting for a commuter partnership? How are the commitments leading to a commuter partnership related to the life domains of work, family, and residence? How can the choice for a commuter partnership be explained in terms of individual and common interests and gender dispositions within the partnership? Relating to each research question, three main conclusions can be drawn.

First of all, the analysis presented in this paper raises questions about the role of choice in family migration decisions, which was central to our first research question. Social theorists have emphasized the role of the choice biography in late modernity. This point of view underlines the importance of individual creativity and personal responsibility in shaping the life course. However, it has also been pointed out that this choice biography is accompanied by risks of failure (Beck 1992; Giddens 1991). Other researchers add that constraints arising from societal factors can significantly diminish the actual choice options available to the individual (Brannen and Nilsen 2005; Favell et al. 2006). We conclude from our analysis that the commuter partnership is usually the outcome of a range of interconnected choices which for many couples are not part of a conscious migration strategy. Our finding that some couples felt they had no realistic alternative to a commuter partnership indicates that the (combinations of) options that couples allow themselves to consider are crucial to the development of their life courses. Although all of our respondents obviously allowed themselves to opt for the unconventional solution of a commuter partnership, there are distinct differences between couples in the rationale behind this choice. Sometimes the choice is negatively motivated by risk avoidance, but in other cases it is looked upon by the couple as a creative household arrangement within the choice set available to them. 
Our second research question concerned the life domains in which the commitments of commuter couples are found. Our findings suggest that, contrary to what most studies into family migration have found, the domain of work is not the only key element in the migration considerations of couples who choose a commuter partnership. Although we selected our respondents in such a way that the job of at least one spouse was part of their considerations, a striking finding is that for many (dual-earner) commuter couples commitments in the family and residential domains are also of great importance in opting for a commuter partnership. From much of the previous research into commuter partnerships, the impression arises that the work domain is paramount to the decision to choose a commuter partnership (Anderson and Spruill 1993; Bunker et al. 1992; Gerstel and Gross 1982, 1984; Gross 1980). However, all these studies focus exclusively on dual-career commuter partnerships, ruling out almost by definition those partnerships in which other considerations besides the work of both partners played a part in this decision. A notable exception is the investigation by Green et al. (1999a, b), who found support for the importance of the residential domain in choosing a commuter partnership. Our finding provides further support for criticism of family migration theories that are based on functionalist assumptions related to income and work, such as the human-capital theory of family migration, which focuses on the (financial) means to be lost or gained by migration. Our analysis shows that there is clearly more to the considerations about migration than calculations of maximizing capital on the family level. This finding explains why commuter partnerships occur not only among dual-career families but also among those with lifestyles that are oriented towards family and residence. Furthermore, our findings show that the commitments leading to the choice for a commuter partnership depend for some on the life-course phase in which the partners are at that point. For others the commuter partnership provides a feasible solution in any life course phase, regardless of the family composition (that is, with or without dependent children).

A third conclusion relates to individual versus common interests and gender dispositions. Whereas it might be expected that commuter partnerships are established in order for both partners to realize their individual preferences, this is certainly not always the case. The variations between couples whose preferences are prioritized (his or her individual interest, or their common interests) shows the intrinsic complexities of intra-household decision making. These complexities strongly relate to the gender dispositions of partners, which are anchored in their everyday thinking and family ideologies. Egalitarian partners were found to mutually reinforce each other's interests and commitments, whether these be found in the work domain or in other life domains. For couples with non-symmetrical gender beliefs we found that substantial sacrifices were demanded of one spouse (usually the female), in order for the other (usually male) partner to pursue a choice biography. Although the women in these couples did not become the traditional trailing wife or tied stayer, the choice for a commuter partnership as an alternative to family migration or not migrating did not benefit the life courses of both individual partners as much as it did for the egalitarian partnerships.

Commuter partnerships can be viewed as an alternative to either family migration or not migrating, but from this study we cannot derive how permanent or short-lived this alternative usually is. In future work, therefore, we plan to examine the changes occurring in commuter partnerships using follow-up interviews with the respondents in our sample. Furthermore, our findings are based on interviews with people who have opted for a commuter partnership. In future studies, an attempt might be made to compare the experiences of people in commuter partnerships with those of people who decided to migrate as a couple or not to migrate. More generally, our findings emphasize that more 
research into intra-household choice structures is of great relevance for further expanding knowledge about the role of linked lives in family migration decisions.

All in all, our results suggest that with the growing pressure on individuals and households to shape their own biographies, and the still rising share of dual-earner households in post-industrial societies, alternative geographical solutions to either family migration or not migrating are likely to become more important in couples' and families' life courses.

Open Access This article is distributed under the terms of the Creative Commons Attribution Noncommercial License which permits any noncommercial use, distribution, and reproduction in any medium, provided the original author(s) and source are credited.

\section{References}

Albert, M. (1993). Capitalism against capitalism. London: Whurr Publishers.

Anderson, E. A., \& Spruill, J. W. (1993). The dual-career commuter family: A lifestyle on the move. Marriage \& Family Review, 19, 131-148.

Bailey, A. J., Blake, M. K., \& Cooke, T. J. (2004). Migration, care, and the linked lives of dual-earner households. Environment and Planning A, 36, 1617-1632.

Beck, U. (1992). Risk society. Towards a new modernity. London: Sage Publications.

Beck, U., \& Beck-Gernsheim, E. (1995). The normal chaos of love. Cambridge: Polity Press.

Becker, H. S. (1960). Notes on the concept of commitment. American Journal of Sociology, 66, 32-40.

Bell, W. (1968). The city, the suburb, and a theory of social choice. In S. Greer, D. L. McElrath, D. W. Minar, \& P. Orleans (Eds.), The new urbanization (pp. 132-168). New York: St Martin's Press.

Bielby, W. T., \& Bielby, D. D. (1992). I will follow him: family ties, gender-role beliefs, and reluctance to relocate for a better job. American Journal of Sociology, 97, 1241-1267.

Bonney, N., \& Love, J. (1991). Gender and migration: Geographical mobility and the wife's sacrifice. The Sociological Review, 39, 335-348.

Bootsma, H. G. (1998). The myth of reurbanization. Location dynamics of households in the Netherlands. Amsterdam: PDOD.

Boyle, P., Cooke, T. J., Halfacree, K., \& Smith, D. (2001). A cross-national comparison of the impact of family migration on women's employment status. Demography, 38, 201-213.

Brannen, J., \& Nilsen, A. (2005). Individualisation, choice and structure: A discussion of current trends in sociological analysis. The Sociological Review, 53, 412-428.

Bunker, B. B., Zubek, J. M., Vanderslice, V. J., \& Rice, R. W. (1992). Quality of life in dual-career families: commuting versus single-residence couples. Journal of Marriage and Family, 54, 399-407.

Clark, W. A. V., \& Davies Withers, S. (2002). Disentangling the interaction of migration, mobility, and labor-force participation. Environment and Planning A, 34, 923-945.

Clark, W. A. V., \& Huang, Y. (2006). Balancing move and work: Women's labour market exits and entries after family migration. Population, Space and Place, 12, 31-44.

Cooke, T. J. (2003). Family migration and the relative earnings of husbands and wives. Annals of the Association of American Geographers, 93, 338-349.

Cooke, T. J., \& Bailey, A. J. (1996). Family migration and the employment of married women and men. Economic Geography, 72, 38-48.

Droogleever Fortuijn, J. (1993). Een druk bestaan. Tijdsbesteding en ruimtegebruik van tweeverdieners met kinderen [A busy life; The use of time and space in dual-earner families]. Amsterdam: Amsterdam University Press.

Dykstra P. A., Kalmijn M., Knijn T. C. M., Komter A. E., Liefbroer A. C., \& Mulder C. H. (2005). Codebook of the Netherlands Kinship Panel Study, a multi-actor, multi-method panel study on solidarity in family relationships, Wave 1. The Hague: Netherlands Interdisciplinary Demographic Institute (NKPS Working Paper No. 4).

Elder, G. H. Jr., Kirkpatrick Johnson, M., \& Crosnoe, R. (2003). The emergence and development of life course theory. In J. T. Mortimer \& M. J. Shanahan (Eds.), Handbook of the life course (pp. 3-19). New York: Kluwer Academic/Plenum Publishers.

Fagnani, J. (1993). Life course and space. Dual careers and residential mobility among upper-middle-class families in the Ile-de-France region. In C. Katz \& J. Monk (Eds.), Full circles. Geographies of women over the life course (pp. 171-187). London: Routledge. 
Favell, A., Feldblum, M., \& Smith, M. P. (2006). The Human face of global mobility: A research agenda. In M. P. Smith \& A. Favell (Eds.), The human face of global mobility. International highly skilled migration in Europe, North America and the Asia-Pacific (pp. 1-25). New Brunswick: Transaction Publishers.

Feijten, P., Mulder, C. H., \& Baizán, P. (2003). Age differentiation in the effect of household situation on first-time homeownership. Journal of Housing and the Built Environment, 18, 233-255.

Gerstel, N., \& Gross, H. E. (1982). Commuter marriages: A review. Marriage \& Family Review, 5, 71-93.

Gerstel, N., \& Gross, H. (1984). Commuter marriage. A study of work and family. New York: Guilford Press.

Giddens, A. (1991). Modernity and self-identity. Cambridge: Polity Press.

Glaser, B. G., \& Strauss, A. L. (1967). The discovery of grounded theory. Chicago: Aldine.

Green, A. E. (1995). The geography of dual career households: A research agenda and selected evidence from secondary data sources for Britain. International Journal of Population Geography, 1, 29-50.

Green, A. E. (1997). A question of compromise? Case study evidence on the location and mobility strategies of dual career households. Regional Studies, 31, 641-657.

Green, A. E., Hogarth, T., \& Shackleton, R. E. (1999a). Long distance living: Dual location households. Bristol: Policy Press.

Green, A. E., Hogarth, T., \& Shackleton, R. E. (1999b). Longer distance commuting as a substitute for migration in Britain: A review of trends, issues and implications. International Journal of Population Geography, 5, 49-67.

Gross, H. E. (1980). Dual-career couples who live apart: Two types. Journal of Marriage and the Family, 42, 567-576.

Hagestad, G. O. (1981). Problems and promises in the social psychology of intergenerational relations. In R. W. Fogel, E. Hatfield, S. B. Kiesler, \& E. Shanas (Eds.), Aging: stability and change in the family. New York: Academic Press.

Halfacree, K. H. (1995). Household migration and the structuration of patriarchy: Evidence from the USA. Progress in Human Geography, 19, 159-182.

Hardill, I. (2002). Gender, migration and the dual career household. New York: Routledge.

Hardill, I., Green, A. E., \& Dudleston, A. C. (1997). The 'blurring of boundaries' between 'work' and 'home': Perspectives from case studies in the East Midlands. Area, 29, 335-343.

Haskey, J. (2005). Living arrangements in contemporary Britain: Having a partner who usually lives elsewhere and Living Apart Together (LAT). Population Trends, 122, 35-45.

Heinz, W. R., \& Krüger, H. (2001). Life course: Innovations and challenges for social research. Current Sociology, 49, 29-45.

Hochschild, A. R. (1997). The time bind. When work becomes home \& home becomes work. New York: Metropolitan Books.

Jacobsen, J. P., \& Levin, L. M. (1997). Marriage and migration: Comparing gains and losses from migration for couples and singles. Social Science Quarterly, 78, 688-709.

Jarvis, H. (1999). The tangled webs we weave: household strategies to co-ordinate home and work. Work, Employment \& Society, 13, 225-247.

Jürges, H. (2006). Gender ideology, division of housework, and the geographic mobility of families. Review of Economics of the Household, 4, 299-323.

Karsten, L. (2003). Family gentrifiers: Challenging the city as a place simultaneously to build a career and to raise children. Urban Studies, 40, 2573-2584.

Komter, A. E. (1985). De macht van de vanzelfsprekendheid. 's-Gravenhage: VUGA Uitgeverij B.V.

Kuijsten, A. (1999). Households, families and kin networks. In L. J. G. Van Wissen \& P. A. Dykstra (Eds.), Population issues. An interdisciplinary focus (pp. 87-122). New York: Kluwer Academic/Plenum Publishers.

Markham, W. T., \& Pleck, J. H. (1986). Sex and willingness to move for occupational advancement: Some national sample results. Sociological Quarterly, 27, 121-143.

Mason, J. (1996). Qualitative researching. London: Sage Publications Ltd.

McHugh, K. E., Hogan, T. D., \& Happel, S. K. (1995). Multiple residence and cyclical migration: A life course perspective. Professional Geographer, 47, 251-267.

Mincer, J. (1978). Family migration decisions. Journal of Political Economy, 86, 749-773.

Mulder, C. H. (1993). Migration dynamics: A life course approach. Amsterdam: Thesis Publishers.

Mulder, C. H. (2002). Levenslopen in de sociaal-ruimtelijke context. Amsterdam: Vossiuspers UvA.

Mulder, C. H., \& Hooimeijer, P. (1999). Residential relocations in the life course. In L. J. G. Van Wissen \& P. A. Dykstra (Eds.), Population issues. An interdisciplinary focus (pp. 159-186). New York: Kluwer Academic/Plenum Publishers.

SCP, \& CBS (2006). Emancipatiemonitor 2006. The Hague: Sociaal Cultureel Planbureau/Centraal Bureau voor de Statistiek. 
Sennett, R. (1998). The corrosion of character. The personal consequences of work in the new capitalism. New York: Norton.

Shihadeh, E. S. (1991). The prevalence of husband-centered migration: Employment consequences for married mothers. Journal of Marriage and the Family, 53, 432-444.

Smits, J. (1999). Family migration and the labour-force participation of married women in the Netherlands, 1977-1996. International Journal of Population Geography, 5, 133-150.

Smits, J., Mulder, C. H., \& Hooimeijer, P. (2003). Changing gender roles, shifting power balance and longdistance migration of couples. Urban Studies, 40, 603-613.

Valentine, G. (1999). Doing household research: Interviewing couples together and apart. Area, 31, 67-74.

Van Ham, M. (2002). Job access, workplace mobility, and occupational achievement. Delft: Eburon Publishers.

Van Ommeren, J. (2000). Job and residential search behaviour of two-earner households. Papers in Regional Science, 79, 375-391.

Willekens, F. J. (1991). Understanding the interdependence between parallel careers. In J. J. Siegers, J. De Jong-Gierveld, \& E. Van Imhoff (Eds.), Female labour market behaviour and fertility. A rationalchoice approach (pp. 11-31). Berlin: Springer-Verlag. 